\title{
DIGIT RATIO AND LATERALITY INDICES: THE CHUVASHIAN STUDY
}

\author{
Leonid Kalichman ${ }^{1}$, Valery Batsevich ${ }^{2}$, Eugene Kobyliansky ${ }^{3}$ \\ ${ }^{1}$ Department of Physical Therapy, Recanati School for Community Health \\ Professions, Faculty of Health Sciences, Ben-Gurion University of the Negev, \\ Beer Sheva, Israel \\ ${ }^{2}$ Research Institute and Museum of Anthropology, Moscow State University, \\ Moscow, Russia \\ ${ }^{3}$ Human Population Biology Research Unit, Department of Anatomy and \\ Anthropology, Tel Aviv University, Tel Aviv, Israel
}

\begin{abstract}
The aim of the present study was to evaluate the association between digit ratio indices (representing the prenatal androgen and estrogen exposure) and different laterality indices, handedness (HDD), the dominant eye (DE), hand clasping (HCL) and arm folding (ARMF) in a large $(\mathrm{N}=1,586)$ Chuvashian population-based sample.

HDD showed a significant association with the right phalangeal length ratio, the right and the left metacarpal ratio and the right ray ratio. Subjects with a right dominant hand had lower right phalangeal, right and left metacarpal and right ray ratios than those with a left dominant hand. This is the first study showing a significant association between the eye dominance and the left metacarpal and the left ray ratios. Subjects with a right DE had lower left metacarpal and left ray ratios than those with the left DE. HCL and ARMF showed no association with radiologically measured digit ratios.
\end{abstract}

Keywords: 2D:4D; digit ratio; laterality, handedness, dominant eye, hand clasping, arm folding, the Chuvashian population

Laterality is the preference most humans show for one side of their body over the other. A majority of humans are right-handed and right-sided. According to Porac \& Coren [30] approximately $88.2 \%$ favor their right hand and $71.1 \%$ 
favor their right eye. The reasons for this are not fully understood. Various laterality indices have been extensively studied and among them handedness (HDD), the dominant eye (DE), hand clasping (HCL) and arm folding (ARMF). Eye dominance is associated with handedness. Previous studies showed that approximately $35 \%$ of right-handers and approximately $57 \%$ of left-handers, were left eye dominant [2]. There are ongoing controversies about the association between HDD and HCL and between HCL and ARMF [11, 17, 25, 32, 33]. Prevalence of laterality indices in the Chuvashian population was previously described [11]

It has been suggested that the index to ring the digit ratio or $2 \mathrm{D}: 4 \mathrm{D}$ ratio is a biomarker of testosterone $[24,31]$ or both androgen and estrogen $[18,40]$ exposure during early intra-uterine life. In adults, men have been found to have a smaller digit ratio than women $[3,9,20,24,35,37]$. During the last decade, the digit ratio has been examined in relation to a number of physiological processes and psychological aspects [31], sporting abilities [22,27], and diverse health conditions $[19,38]$. The association between the digit ratio and laterality has been evaluated by several researchers, but the number of studies devoted specifically to this problem is scarce, concentrating mainly on hand skills. Manning et al. [23] evaluated the association between lateralized hand performance and the digit ratio. Authors reported that a low right hand digit ratio (masculine type) was significantly associated with a reduction in the rightward performance asymmetry. Fink et al. [6] reported that in children with right dominance, the high digit ratio associates with the enhanced right-hand skill, and the low digit ratio correlates with the improved left-hand skill. Stoyanov et al. [36] found that the difference between the right and the left digit ratio was significantly lower in left-handers than in right-handers. Voracek et al. [39], in a sample of 54 tournament fencers, found that the right hand digit ratio was significantly lower in left-handed fencers compared to right-handed ones. Nicholls et al. [26] in a study of 600 students showed a more masculine pattern of the digit ratio (lower index/ring ratio) in left-handers, a more feminine pattern of the digit ratio in right-handers. In a large internet sample, Manning and Peters [21] found a statistically significant association between the writing hand preference and the digit ratio. The left hand digit ratio was significantly larger than the ratio of the right hand in left-handed writers of both sexes and the right hand digit ratio was larger than the left hand ratio in male and female right-handed writers. On the other hand, we found no studies evaluating the association between the digit ratio and other laterality indices (HCL and ARMF). 
The aim of the present study was to evaluate the association between the digit ratio indices (representing the prenatal environment, i.e., early androgen and estrogen exposure) and different laterality indices (HDD, DE, HCL and ARMF) in a Chuvashian population-based sample.

\section{METHODS}

Study design: Cross-sectional observational study.

Sample: The sampled population were Chuvashians from numerous small villages in the Volga region, the Chuvashia and Bashkortostan Autonomies of the Russian Federation. The sample was described in detail elsewhere [10, 12]. The participants of the study were randomly chosen volunteers with similar living, economic, and professional conditions. Most individuals were employed in agriculture or in other physical labor occupations. Individuals with deformation/trauma at either hand were excluded. Data on sex, age, weight, height and occupation were gathered from self-completed questionnaires and confirmed during the interview. Single plain postero-anterior X-rays of both hands were acquired from each subject in addition to the necessary examinations. All the study procedures were consensual and were performed only after the signed informed consent was received. The project was approved by the Helsinki Ethics Committee of Tel-Aviv University.

Evaluation of digit ratio: X-rays were taken using a standard procedure as described in detail by Pavlovsky and Kobyliansky $[16,28]$. All the x-rays were digitized and the digit ratio measurements were made on the digital image using UTHSCSA ImageTool free software (available at http://compdent.uthscsa.edu/dig/itdesc.html). This method was chosen because it was found to be more reliable than the digit ratio evaluation on a plain $\mathrm{x}$-ray using calipers [14]. The digit ratio was evaluated according to the commonly accepted rule [19, $34]$. The measurements performed on the index (2D) and ring (4D) fingers of both hands included: 1) the distance between the mid-point of the base of the proximal phalanx and the mid-point of the tip of the distal phalanx; and 2) the distance between the mid-point of the base and the mid-point of the tip of the metacarpals. There was a previous study that used a metacarpal length ratio [34]. It was found that both the phalanges and metacarpals both contribute to the variation in 2D:4D ratio. One observer performed all the measurements and entered the results directly into a Microsoft Excel file. X-rays of 50 randomly selected hands were measured twice by the same observer in order to estimate 
the reliability of readings. The intraclass correlation coefficient (ICC) for finger measurements ranged between $0.95(0.88-0.98)$ and 0.96 (0.89-0.98).

Laterality evaluation: Four indices of laterality, that were previously described in the Chuvashian population [11] were used in the present study: HDD, HCL, ARMF and DE. To identify the writing hand preference (HDD in this study), participants were asked: "Which hand do you write with?" The answer was confirmed by researchers during a writing exercise. To identify HCL and ARMF, a standard method [8] was used. Right or left HCL and ARMF were determined according to which fingers (of the right or the left hand) or which arm assumed the uppermost position during the testing. To determine the DE, the subject was asked to look through a $1 \mathrm{~cm}$. hole in a cardboard held at a distance of $30-35 \mathrm{~cm}$ from the face focusing on the stationary object one meter away. Then the subject was asked to close and open one eye and then the other. The $\mathrm{DE}$ was determined according to which eye still focused on the object, when the other eye was closed.

Statistical analysis: All the computations were performed using SPSS 17.0 for Windows (SPSS, Chicago, IL, USA). The mean and the standard deviation for age and body mass index (BMI), digit ratios and the prevalence of laterality indices (HDD, HCL, ARMF and DE) were calculated using descriptive statistics. Comparisons between males and females were performed by the one-way ANOVA (for age and BMI) or the $\chi^{2}$ test (for laterality indices).

Associations between laterality indices (dichotomous variables) and phalangeal, metacarpal and ray (combined phalangeal + metacarpal) length ratios (continues variables) were calculated in univariate (ANOVA) and multivariate (linear regression) analyses, adjusted for age, sex and BMI.

\section{RESULTS}

The study sample (Table 1) included 803 males (the mean age 46.98 \pm 17.09 ) and 783 females (the mean age $48.65 \pm 16.62)$. the male BMI $(23.19 \pm 3.26)$ was lower than in the females $(25.16 \pm 4.87)(\mathrm{p}<0,001)$. Left-handedness was prevalent in $9.08 \%$ of males and $9.98 \%$ of females; left DE in $22.84 \%$ of males and $21.81 \%$ of females; left HCL in $47.63 \%$ of males and $49.32 \%$ of females and left ARMF in $52.02 \%$ of males and $58.98 \%$ of females. Statistically, a significant difference between sexes was found only in ARMF ( $\mathrm{p}=0.016)$. 
Table 1. Characteristics of the study sample

\begin{tabular}{|c|c|c|c|c|}
\hline \multicolumn{2}{|c|}{ Characteristic } & Men & Women & $\begin{array}{l}\text { Comparison between sexes } \\
(p-v a l u e)\end{array}$ \\
\hline \multicolumn{2}{|c|}{ No. of participants } & 803 & 738 & \\
\hline \multicolumn{2}{|c|}{ Age (years) } & $46.98 \pm 17.09$ & $48.65 \pm 16.62$ & $0.053^{*}$ \\
\hline \multicolumn{2}{|c|}{ BMI $\left(\mathrm{kg} / \mathrm{m}^{2}\right)$} & $23.19 \pm 3.26$ & $25.16 \pm 4.87$ & $<0.001^{*}$ \\
\hline \multirow{2}{*}{ HDD } & Right & $90.92 \%$ & $90.02 \%$ & \multirow{2}{*}{$0.075^{\star \star}$} \\
\hline & Left & $9.08 \%$ & $9.98 \%$ & \\
\hline \multirow{2}{*}{ DE } & Right & $77.16 \%$ & $78.19 \%$ & \multirow{2}{*}{$0.676^{\star \star}$} \\
\hline & Left & $22.84 \%$ & $21.81 \%$ & \\
\hline \multirow{2}{*}{$\mathrm{HCL}$} & Right & $52.37 \%$ & $50.68 \%$ & \multirow{2}{*}{$0.559^{\star *}$} \\
\hline & Left & $47.63 \%$ & $49.32 \%$ & \\
\hline \multirow{2}{*}{ ARMF } & Right & $47.98 \%$ & $41.02 \%$ & \multirow{2}{*}{$0.016^{* *}$} \\
\hline & Left & $52.02 \%$ & $58.98 \%$ & \\
\hline
\end{tabular}

* Results of one way ANOVA, ${ }^{*}$ results of $x^{2}$ test. Statistically significant associations at $p \leq 0.05$ level marked in bold. BMI - body mass index; DE - dominant eye; $\mathrm{HCL}$ - hand clasping; HDD - handedness; ARMF - arm folding.

In the Chuvashian sample, the right phalangeal ratio was $0.907 \pm 0.024$ in males and $0.912 \pm 0.020$ in females; the left phalangeal ratio was $0.909 \pm 0.022$ in males and $0.914 \pm 0.020$ in females; the right metacarpal ratio was $1.176 \pm 0.032$ in males and $1.172 \pm 0.032$ in females; the left metacarpal ratio was $1.168 \pm 0.031$ in males and $1.164 \pm 0.031$ in females and finally, the right ray ratio was $1.012 \pm 0.019$ in males and $1.015 \pm 0.018$ in females; the left ray ratio was $1.011 \pm 0.018$ in males and $1.012 \pm 0.018$ in females.

Associations between laterality indices and radiologically measured digit ratios are shown in Table 2 . As it can be seen, unadjusted and adjusted for age, sex and BMI associations revealed similar results. The mean values \pm the standard deviation of digit ratios according to the dominant side in the studied laterality indices can be seen in Table 3 . HDD showed a significant association with the right phalangeal length ratio $(\mathrm{p}=0.049)$, the right and the left metacarpal ratio ( $\mathrm{p}=0.012$ and $\mathrm{p}=0.007$, correspondingly) and right ray ratio $(\mathrm{p}=0.002)$. Subjects with a right dominant hand had lower right phalangeal, right and left metacarpal and the right ray ratios than those with a left dominant hand. DE showed a significant association with left metacarpal $(\mathrm{p}=0.033)$ and left ray $(\mathrm{p}=0.017)$ ratios. The subjects with the right $\mathrm{DE}$ had lower left metacarpal and left ray ratios than those with the left DE. HCL and ARMF showed no association with radiologically measured digit ratios. 
Table 2. Associations between radiographically measured $2 \mathrm{D}: 4 \mathrm{D}$ ratios and indices of laterality ( $p$-values)

\begin{tabular}{|c|c|c|c|c|c|c|}
\hline & & $\begin{array}{l}\text { Type of } \\
\text { analysis }\end{array}$ & HDD & DE & HCL & ARMF \\
\hline \multirow{4}{*}{$\begin{array}{l}\text { Phalangeal length } \\
\text { ratio }\end{array}$} & \multirow{2}{*}{ Right } & Univariate $^{\star}$ & 0.049 & 0.968 & 0.408 & 0.234 \\
\hline & & Adjusted $^{\star *}$ & 0.051 & 0.860 & 0.479 & 0.420 \\
\hline & \multirow{2}{*}{ Left } & Univariate $^{*}$ & 0.279 & 0.269 & 0.134 & 0.528 \\
\hline & & Adjusted $^{\star *}$ & 0.261 & 0.255 & 0.189 & 0.797 \\
\hline \multirow{4}{*}{$\begin{array}{l}\text { Metacarpal length } \\
\text { ratio }\end{array}$} & \multirow{2}{*}{ Right } & Univariate $^{*}$ & 0.012 & 0.577 & 0.214 & 0.589 \\
\hline & & Adjusted $^{\star \star}$ & 0.012 & 0.659 & 0.158 & 0.503 \\
\hline & \multirow{2}{*}{ Left } & Univariate* & 0.007 & 0.033 & 0.841 & 0.901 \\
\hline & & Adjusted $^{\star \star}$ & 0.006 & 0.042 & 0.640 & 0.783 \\
\hline \multirow{4}{*}{ Ray length ratio } & \multirow{2}{*}{ Right } & Univariate $^{\star}$ & 0.002 & 0.560 & 0.969 & 0.123 \\
\hline & & Adjusted $^{\star \star}$ & 0.002 & 0.517 & 0.901 & 0.189 \\
\hline & \multirow{2}{*}{ Left } & Univariate $^{*}$ & 0.278 & 0.017 & 0.548 & 0.501 \\
\hline & & Adjusted $^{\star \star}$ & 0.296 & 0.016 & 0.730 & 0.621 \\
\hline
\end{tabular}

* One way ANOVA; ** Linear regression analysis with adjustment for age, sex and BMI; Statistically significant associations at $\mathrm{p} \leq 0.05$ level marked in bold. $\mathrm{DE}$ - dominant eye; $\mathrm{HCL}$ - hand clasping; HDD - handedness; ARMF - arm folding.

Table 3. Mean values \pm standard deviation of $2 \mathrm{D}: 4 \mathrm{D}$ ratios according to the dominant side in studied laterality indices

\begin{tabular}{|c|c|c|c|c|c|c|}
\hline & & $\begin{array}{l}\text { Dominant } \\
\text { side }\end{array}$ & HDD & $\mathrm{DE}$ & HCL & ARMF \\
\hline \multirow{4}{*}{$\begin{array}{l}\text { Phalan- } \\
\text { geal } \\
\text { length } \\
\text { ratio }\end{array}$} & \multirow{2}{*}{ Right } & Right & $0.909 \pm 0.022$ & $0.909 \pm 0.022$ & $0.910 \pm 0.022$ & $0.908 \pm 0.021$ \\
\hline & & Left & $0.913 \pm 0.023$ & $0.909 \pm 0.024$ & $0.909 \pm 0.022$ & $0.910 \pm 0.023$ \\
\hline & \multirow{2}{*}{ Left } & Right & $0.912 \pm 0.022$ & $0.911 \pm 0.021$ & $0.912 \pm 0.021$ & $0.911 \pm 0.022$ \\
\hline & & Left & $0.909 \pm 0.022$ & $0.913 \pm 0.023$ & $0.910 \pm 0.022$ & $0.912 \pm 0.022$ \\
\hline \multirow{4}{*}{$\begin{array}{l}\text { Meta- } \\
\text { carpal } \\
\text { length } \\
\text { ratio }\end{array}$} & \multirow{2}{*}{ Right } & Right & $1.175 \pm 0.032$ & $1.175 \pm 0.032$ & $1.174 \pm 0.031$ & $1.175 \pm 0.032$ \\
\hline & & Left & $1.183 \pm 0.034$ & $1.176 \pm 0.031$ & $1.177 \pm 0.033$ & $1.176 \pm 0.033$ \\
\hline & \multirow{2}{*}{ Left } & Right & $1.164 \pm 0.031$ & $1.164 \pm 0.032$ & $1.165 \pm 0.030$ & $1.165 \pm 0.032$ \\
\hline & & Left & $1.173 \pm 0.033$ & $1.169 \pm 0.030$ & $1.165 \pm 0.032$ & $1.165 \pm 0.031$ \\
\hline \multirow{4}{*}{$\begin{array}{l}\text { Ray } \\
\text { length } \\
\text { ratio }\end{array}$} & \multirow{2}{*}{ Right } & Right & $1.013 \pm 0.018$ & $1.014 \pm 0.018$ & $1.014 \pm 0.018$ & $1.013 \pm 0.018$ \\
\hline & & Left & $1.019 \pm 0.019$ & $1.015 \pm 0.019$ & $1.014 \pm 0.019$ & $1.015 \pm 0.019$ \\
\hline & \multirow{2}{*}{ Left } & Right & $1.011 \pm 0.018$ & $1.011 \pm 0.018$ & $1.012 \pm 0.018$ & $1.011 \pm 0.018$ \\
\hline & & Left & $1.013 \pm 0.019$ & $1.014 \pm 0.018$ & $1.011 \pm 0.018$ & $1.012 \pm 0.018$ \\
\hline
\end{tabular}

$\mathrm{DE}$ - dominant eye; $\mathrm{HCL}$ - hand clasping; HDD - handedness; ARMF - arm folding. 


\section{DISCUSSION}

The most frequent combination of the studied laterality indices in the Chuvashian population-based sample was the right dominance in HDD, DE and HCL and the left dominance in ARMF. The left writing hand preference was prevalent in $9.08 \%$ of males and $9.98 \%$ of females; the left DE in $22.84 \%$ of males and $21.81 \%$ of females; the left HCL in $47.63 \%$ of males and $49.32 \%$ of females and left ARMF in $52.02 \%$ of males and $58.98 \%$ of females. The left HDD is comparable to the ones reported in other populations [1, 17, 21,29].

In our study, the digit ratio was assessed by radiographic evaluation, an infrequent way of assessing digit ratios, but which has been previously used in several studies [20,24, 27, 34]. Our previous study, performed on the same sample [13], showed that the $2 \mathrm{D}: 4 \mathrm{D}$ phalangeal ratio is measurable on radiographs and varies on male and female hands in accordance with the majority of published studies.

In our study, HDD showed a significant association with the right phalangeal length ratio, the right and the left metacarpal ratio and the right ray ratio. The subjects with a right dominant hand had lower right phalangeal, right and left metacarpal and right ray ratios than those with a left dominant hand. As we mentioned before, the association between the digit ratio and HDD was found in several previous studies [21, 26, 36, 39]. However, contrary to our results, these studies demonstrated that left-handed individuals had a lower, more masculine digit ratio. We cannot explain the observed differences which may be due to radiographic measurements of the digit ratio in our study vs. direct, indirect and self-measurements in other studies. It may also be a unique feature of the Chuvashian population and additional studies should be performed on other samples to determine if our findings were just a random deviation or if this type of association can also be found in other samples.

The definition of DE is "the eye controlling binocular function". It represents the tendency to prefer visual input from one eye to the other [15]. Eye dominance may determine the deviating eye in strabismus [4], is thought to be important in the development and control of reading [5], and may have a role in the etiology of dyslexia [7]. However, the role of eye dominance in disease etiology is poorly understood. To the best of our knowledge, this study is one of the first showing a significant association between DE and left metacarpal $(\mathrm{p}=0.033)$ and left ray $(\mathrm{p}=0.017)$ ratios. The subjects with the right $\mathrm{DE}$ had lower left metacarpal and left ray ratios than those with the left $\mathrm{DE}$. These findings should be replicated in other samples.

HCL and ARMF showed no association with radiologically measured digit ratios. 
Study limitations: The combined ray measurements did not include the thickness of metacarpophalangeal joint cartilage and finger tips soft tissues because they were generated by adding the phalanx to the metacarpal length rather than measuring directly from the metacarpal base to the fingertip.

\section{CONCLUSIONS}

In our population-based study, HDD showed a significant association with the right phalangeal length ratio, the right and the left metacarpal ratio and the right ray ratio. The subjects with a right dominant hand had lower right phalangeal, right and left metacarpal and right ray ratios than those with a left dominant hand. This study demonstrated a significant association between eye dominance and the left metacarpal and left ray ratios. The subjects with the right DE had lower left metacarpal and left ray ratios than those with the left DE.

\section{ACKNOWLEDGEMENTS}

The authors thank Mrs Phyllis Curchack Kornspan for her editorial services.

\section{REFERENCES}

1. Arensburg B., Hershkovitz I., Kobyliansky E., Micle S. (1979). Southern Sinai Bedouin tribes: preliminary communication on an anthropological survey. Bull et Mém de la Soc d'Anthrop de Paris, 363-372.

2. Bourassa D. C., McManus I. C., Bryden M. P. (1996). Handedness and eyedominance: a meta-analysis of their relationship. Laterality 1, 5-34.

3. Buck J. J., Williams R. M., Hughes I. A., Acerini C. L. (2003), In-utero androgen exposure and 2nd to 4th digit length ratio-comparisons between healthy controls and females with classical congenital adrenal hyperplasia. Hum Reprod 18, 976-979.

4. Coren S., Duckman R. H. (1975). Ocular dominance and amblyopia. Am J Optom Physiol Opt 52, 47-50.

5. Dunlop P. (1992). Development of dominance in the central binocular field. Br Orthopt J 49, 31-35.

6. Fink B., Manning J. T., Neave N., Tan U. (2004). Second to fourth digit ratio and hand skill in Austrian children. Biol Psychol 67, 375-384.

7. Fowler M. S. (1983). Consideration of ocular motor dominance as an etiological factor in some orthoptic problems. Br Orthopt J 40, 43-45.

8. Freire-Maia A., Freire-Maia N., Quelce-Salgado A. (1960). Genetic analysis in Russian immigrants. PTC sensitivity, finger prints, color vision, hand clasping, and arm folding. Am J Phys Anthropol 18, 235-240. 
9. Galis F., Ten Broek C. M., Van Dongen S., Wijnaendts L.C. Sexual dimorphism in the prenatal digit ratio (2D:4D). Arch Sex Behav 39, 57-62.

10. Kalichman L., Cohen Z., Kobyliansky E., Livshits G. (2002). Interrelationship between bone aging traits and basic anthropometric characteristics. Am J Hum Biol 14, 380-390.

11. Kalichman L., Korostishevsky M., Kobyliansky E. (2008). Laterality indices in the Chuvashian population. Anthropol Anz 66, 409-418.

12. Kalichman L., Livshits G., Kobyliansky E. (2006). Indices of body composition and chronic morbidity: a cross-sectional study of a rural population in central Russia. Am J Hum Biol 18, 350-358.

13. Kalichman L., Zorina D., Batsevich V., Kobyliansky E. (2013). 2D:4D finger length ratio in a Chuvashian population. Journal of Comparative Human Biology HOMO 64, 233-240.

14. Kemper C. J., Schwerdtfeger A. (2009). Comparing indirect methods of digit ratio (2D:4D) measurement. Am J Hum Biol 21, 188-191.

15. Khan A. Z., Crawford J. D. (2001). Ocular dominance reverses as a function of horizontal gaze angle. Vision Res 41, 1743-1748.

16. Kobyliansky E., Livshits G., Pavlovsky O. (1995). Population biology of human aging: methods of assessment and sex variation. Hum Biol 67, 87-109.

17. Kobyliansky E., Micle S., Arensburg B. (1978). Handedness, hand-clasping and arm-folding in Israeli males. Ann Hum Biol 5, 247-251.

18. Lutchmaya S., Baron-Cohen S., Raggatt P., Knickmeyer R., Manning J. T. (2004). 2nd to 4th digit ratios, fetal testosterone and estradiol. Early Hum Dev 77, 23-28.

19. Manning J. T., Bundred P. E. (2000). The ratio of 2 nd to 4 th digit length: a new predictor of disease predisposition? Med Hypotheses 54, 855-857.

20. Manning J. T., Churchill A. J., Peters M. (2007). The effects of sex, ethnicity, and sexual orientation on self-measured digit ratio (2D:4D). Arch Sex Behav 36, 223-233.

21. Manning J. T., Peters M. (2009). Digit ratio (2D:4D) and hand preference for writing in the BBC Internet Study. Laterality 14, 528-540.

22. Manning J. T., Taylor R. P. (2001). Second to fourth digit ratio and male ability in sport: implications for sexual selection in humans. Evolution and Human Behavior 22, 61-69.

23. Manning J. T., Trivers R. L., Thornhill R., Singh D. (2000). The 2nd:4th digit ratio and asymmetry of hand performance in Jamaican children. Laterality 5, 121-132.

24. McIntyre M. H. (2006). The use of digit ratios as markers for perinatal androgen action. Reprod Biol Endocrinol 4, 10.

25. McManus I. C., Mascie-Taylor C. G. (1979). Hand-clasping and arm-folding: a review and a genetic model. Ann Hum Biol 6, 527-558.

26. Nicholls M. E., Orr C. A., Yates M. J., Loftus A. M. (2008). A new means of measuring index/ring finger (2D:4D) ratio and its association with gender and hand preference. Laterality 13, 71-91. 
27. Paul S. N., Kato B. S., Hunkin J. L., Vivekanandan S., Spector T. D. (2006). The big finger: the second to fourth digit ratio is a predictor of sporting ability in women. Br J Sports Med 40, 981-983.

28. Pavlovsky O., Kobyliansky E. (1997). Population Biology of Human Aging Angelo Pontecorboli Editore, Firenze, Italy

29. Pelecanos M. (1969). Some Greek data on handedness, hand clasping and arm folding. Hum Biol 41, 275-278.

30. Porac C., Coren S. (1981).Lateral preferences and human behavior. SpringerVerlag, New York.

31. Putz D., Gaulin S., Sporter R., McBurney D. (2004). Sex hormones and finger length: What does 2D:4D indicate? Evolution and Human Behavior 25, 182-199.

32. Reiss M. (1998). Arm folding-an overview. Anthropologischer Anzeiger 56.

33. Reiss M. (1999). The genetics of hand-clasping - a review and a familial study. Annals of Human Biology 26, 39-48.

34. Robertson J., Zhang W., Liu J. J., Muir K. R., Maciewicz R. A., Doherty M. (2008). Radiographic assessment of the index to ring finger ratio (2D:4D) in adults. J Anat 212, 42-48.

35. Saino N., Rubolini D., Romano M., Boncoraglio G. (2007). Increased egg estradiol concentration feminizes digit ratios of male pheasants (Phasianus colchicus). Naturwissenschaften 94, 207-212.

36. Stoyanov Z., Marinov M., Pashalieva I. (2009). Finger length ratio (2D:4D) in left- and right-handed males. Int J Neurosci 119, 1006-1013.

37. Trivers R., Manning J., Jacobson A. (2006). A longitudinal study of digit ratio (2D:4D) and other finger ratios in Jamaican children. Horm Behav 49, 150-156.

38. Vehmas T., Solovieva S., Leino-Arjas P. (2006). Radiographic 2D:4D index in females: no relation to anthropometric, behavioural, nutritional, health-related, occupational or fertility variables. J Negat Results Biomed 5, 12.

39. Voracek M., Reimer B., Ertl C., Dressler S. G. (2006). Digit ratio (2D:4D), lateral preferences, and performance in fencing. Percept Mot Skills 103, 427-446.

40. Zheng Z., Cohn M. J. (2011). Developmental basis of sexually dimorphic digit ratios. Proc Natl Acad Sci U S A 108, 16289-16294.

\section{Address for correspondence:}

Leonid Kalichman

Department of Physical Therapy

Recanati School for Community Health Professions

Faculty of Health Sciences

Ben-Gurion University of the Negev, Beer Sheva, Israel

E-mail: kleonid@bgu.ac.il, kalichman@hotmail.com. 